\title{
SYNTHESIS AND CHARACTERISATION OF BISPHENOL A NOVOLAC EPOXY RESINS FOR COATING APPLICATIONS
}

\author{
N. O. SHAKER
}

Egyptian Petroleum Research Institute, Nasr City 11727, Cairo, Egypt

\begin{abstract}
Bisphenol A novolacs were synthesized in a melting process using para formaldehyde, and in a solution process using formalin solution and oxalic acid catalyst. ${ }^{1} \mathrm{H}-\mathrm{NMR}$ investigations show a higher content of methylene bridges in the novolacs synthesized by the melting process. These novolacs were analyzed by GPC and FT-IR spectroscopy. The bisphenol A novolac was cured with 1,2-amino ethyl piperazine (AEP) as a curing agent for epoxy resins. The networks synthesized were evaluated as organic coatings for steel. The mechanical properties of the cured epoxy resins were tested and the chemical resistances of the cured resins were evaluated through salt spray resistance, hot water, solvents, acid and alkali resistance measurements. The data indicate that the cured epoxy resins have excellent chemical resistance as organic coatings among other resins.
\end{abstract}

\section{Introduction}

Epoxy novolacs are multifunctional epoxides based on phenol formaldehyde novolacs. Epoxy phenol novolac resins have attained commercial importance (1-3). When cured with polyamide or aliphatic polyamines and their adducts, epoxy novolacs show improvement over bisphenol A epoxies, but the critical performance of each cure is limited by the performance of the curing agent. Novolac-cured epoxies are widely employed in molding and sealing compounds for the production of electronic devices. Commercial novolacs are used on the basis of phenol or cresol [4-5]. Modelling reactions of epoxy-phenol systems are investigated in the literature [6-8], while no investigations about bisphenol A novolac-cured epoxy resins have been yet reported.

The simplest diepoxide formed is the glycidyl ether derivatives. Although these materials are used as adhesives, they suffer from lack of flexibility, which arises from rigid aromatic groups in the short chains. Improvements in flexibility can be obtained by incorporation of long chain compounds into the resin before curing. The aim of the present study is directed towards the introduction of methylene group between aromatic groups of bisphenol A to improve both the adhesion and flexibility properties of epoxy resins. In this respect, bisphenol A novolacs were synthesized in a melting process using para formaldehyde, and in a solution process using a formalin solution and oxalic acid catalyst. 1-(2-Amino ethyl) piperazine (AEP) was selected as a suitable amine curing agent to produce organic coatings. 


\section{Experimental Materials:}

Diglycidylether of bisphenol A (DGEBA) was recrystallized from acetonemethanol mixture (20:80, v/v); m.p. $44^{\circ} \mathrm{C}$ [9]. 1-(2-Amino ethyl) piperazine (AEP) was used as a hardner. High purity acetone, toluene and pyridine were used as received. All chemicals were supplied by the Aldrich chemical company.

\section{Techniques}

\section{Methylation of bisphenol A}

Different molar ratios of bisphenol A and para formaldehyde were used for the synthesis of the novolacs, they varied between 0.167 and $0.495 \mathrm{~mol}$ formaldehyde to $0.438 \mathrm{~mol}$ bisphenol A. The mixtures were heated to $180^{\circ} \mathrm{C}$ in a one-necked flask with a reflux condenser and a drying tube filled with glass wool. After $30 \mathrm{~min}$ the reflux condenser was removed and the water formed was distilled off. Then the temperature of the reaction mixture raised up to $200^{\circ} \mathrm{C}$ for about 5 minutes.

For the bisphenol A novolac synthesis in solution process, $0.5 \mathrm{~mol}$ of bisphenol A was refluxed with $1.5 \mathrm{~mol}$ of $37 \%$ formalin solution and $1 \mathrm{~g}$ dehydrated oxalic for $90 \mathrm{~min}$. then $100 \mathrm{ml}$ water were added while stirring. After depositing, the water layer was decanted and the residual water of the lower viscous layer was removed in vacuo at $140^{\circ} \mathrm{C}$. A colourless product was obtained in a yield of $65 \%$.

\section{Preparation of diglycidyl ether bisphenol A}

In a humidity-protected 500ml glass reactor equipped with a mechanical stirrer, dropping funnel and a condenser, the purified methylol derivative of bisphenols ( $0.11 \mathrm{~mol}$ ) were mixed with $1 \%$ of $\mathrm{BF}_{3} \cdot \mathrm{ET}_{2} \mathrm{O}$ and heated at $40^{\circ} \mathrm{C}$. Epichlorohydrine was gradually added to the reaction mixture during $2 \mathrm{hrs}$. The reaction mixture was heated at $125^{\circ} \mathrm{C}$ for $30 \mathrm{~min}$ and after cooling to $40^{\circ} \mathrm{C}, 0.22 \mathrm{~mol}$ of $\mathrm{NaOH}$ (as $50 \%$ of aqueous solution) was added. Temperature of the reaction mixture was raised up to $80^{\circ} \mathrm{C}$ for $30 \mathrm{~min}$. After cooling, the mixture was neutralized with $50 \mathrm{ml}$ of acetic acid (50\%); and $150 \mathrm{ml}$ of toluene was added and the reaction mixture was filtered to remove sodium salts. The filtrate was washed four times with $150 \mathrm{ml}$ of hot water $\left(60-80^{\circ} \mathrm{C}\right)$, then toluene was evaporated from organic layer by rotary evaporator.

The diglycidyl ether of methylated bisphenols derived from acetone, benzaldehyde and acetophenone derivatives were designated as DGMBA and DGMBBA and DGMBAC, respectively. The products were obtained as viscous products and the epoxy content (EC) was determined as reported method [10]. 


\section{Physical measurements:}

The prepared epoxy resins were dissolved in $\mathrm{CDCI}_{3}$ and analyzed using a Jeol ${ }^{1} \mathrm{HNMR}$ spectrometer model JNM-EX (270 MHz) to determine their chemical structures. GPC analyses of the novolacs were carried out on a column set (PS 4/ps $20 \mathrm{HI}$ BAR columns, Merck) with exclusion limits from 100 up to $20000 \mathrm{~g} / \mathrm{mol}$ (polystyrene in tetrahydrofuran). Tetrahydrofuran as eluent and a refractive index detector were used. The glass transition temperatures (Tg) of the synthesized novolacs were measured on a Perkin Elmer DSC in a temperature range of 30 to $210^{\circ} \mathrm{C}$ with a scanning rate of $5^{\circ} \mathrm{C} / \mathrm{min}$. The curing exotherms of the prepared epoxy resins were measured in the presence of different weight ratios of AEP hardener as described in previous works [11-13]. The curing exotherms were determined at two different temperatures 40 and $60^{\circ} \mathrm{C}$.

\section{Testing of the Coatings:}

It is common to use mild steel panels $(15 \mathrm{~cm} \times 10 \mathrm{~cm})$ to evaluate the different properties of coatings. The other side of panels was coated and protected against corrosion environments by using coal tar epoxy primer.

The tested side was blasted and cleaned to apply the coating materials. Then the panels were subjected to different testing procedure to evaluate their mechanical properties and their durability as follows:-

- $\quad$ Adhesion strength (pull-off), ASTM D 4541-95

- $\quad$ Pencil hardness ASTM D 3363-92a

- $\quad$ Impact ASTM D 2794

- $\quad$ T- bend test ASTM D 522-93a

Chemical resistances were measured according to ASTM methods as reported in a previous study [13].

- $\quad$ Hot water ASTM D 870-92,

- $\quad$ Acid and alkali resistances ASTM D1647-89

The acid and alkali resistances of coated panels were determined after immersion in $10 \%$ of $\mathrm{HCI}$ and $5 \%$ of $\mathrm{NaOH}$ aqueous solutions using distilled water. The duration of the test was 90 days at $38^{\circ} \mathrm{C}$. The degree of adhesion and visual inspection of blister and cracks were evaluated for the coated panels.

- $\quad$ Salt spray resistance

The coated panels were evaluated for salt-spray resistance in accordance with ASTM B117-73. The test conditions were $35^{\circ} \mathrm{C}\left( \pm 1.5^{\circ} \mathrm{C}\right), 95 \pm 5 \%$ relative humidity, and $5 \%$ weigh percent of aqueous sodium chloride solution. 
- $\quad$ Solvent resistance ASTM 02792

\section{Results and discussion}

The reaction of bisphenol A with formaldehyde in a basic medium leads to resins of the resol type [14-16]. ${ }^{1} \mathrm{H}-\mathrm{NMR}$ and FT-IR-investigations on bisphenol Aformaldehyde resins show the formation of resol resins in the presence of catalysts, but in the absence of a catalyst novolac type resins are formed [17]. The novolac formation by catalysis of the bisphenol A-formaldehyde reaction with oxalic acid has already been investigated [18-19], but no information about the structure of these novolacs was given. bisphenol A novolacs were synthesized in the absence of solvent and catalyst to produce epoxy resins. "Bisphenol-A and para formaldehyde were converted to the bisphenol A novolac [product (1) ]. The molar ratio between paraformaldehyde and bisphenol A used for the syntheses of the novolacs was varied between 0.167 and 0.495 mol para formaldehyde and 0.438 mol bisphenol A (Table 1).

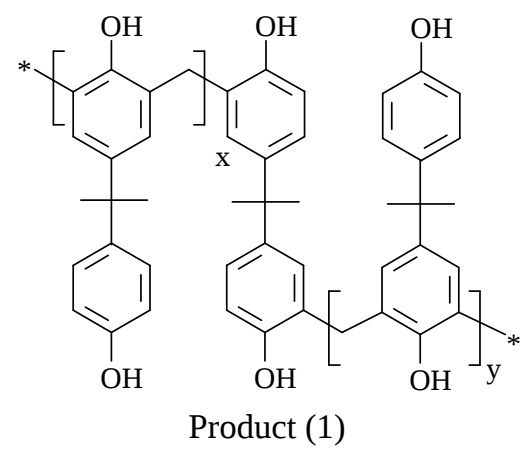

The molar mass of the novolacs synthesized $(\mathrm{Mn})$ rises with increasing concentration of paraformaldehyde in the reaction mixture. The glass transition temperatures of the novolacs ( $\mathrm{Tg}$ ) do not significantly depend on the molar ratio of the reacting components, but the specific heat capacities $(\mathrm{H})$ determined in the glass transition state decreased with increasing paraformaldehyde content in the reaction mixture (Table 1). The oligomer distribution of the novolacs was estimated by GPC. The GPC-chromatogram of two examples of the novolacs synthesized are given in Figure (1). It can be seen that the novolacs contain a relatively high concentration of unreacted bisphenol A. From the literature the possibility of a quantitative determination of the low-molecular-weight oligomers in phenol or p-cresolformaldehyde resins [20-21] and of the phenol content [22] is known. A calibration with model substances is a prerequisite. Therefore, only the area-\% of the bisphenol A peaks in the GPC- chromatograms as a measure for the bisphenol A content were 
determined and related to the reaction conditions. The dependence of this bisphenol A peak area-\% on the molar ratio of the reacting components shows that the content of unreacted bisphenol A decreases if more para formaldehyde is used in the synthesis (Figure 2). Increasing the mole ratio of para formaldehyde during synthesis of the novolacs leads to a product of higher molecular mass (Table 1). The concentration of the methylene bridges in the novolacs synthesized was estimated from ${ }^{1} \mathrm{H}$-NMR spectra. In this respect, ${ }^{1} \mathrm{HNMR}$ spectrum of BP-10 is represented in Figure 3. The ratio between the peaks at chemical shift 2.2 and $0.8 \mathrm{ppm}$ which represent methylene and methyl groups, respectively was used to determine the methylene content. The concentration of the methylene bridges in the novolacs synthesized was estimated from ${ }^{1} \mathrm{H}-\mathrm{NMR}$ spectra. Figure 4 shows the ratio of the methylene and methyl protons determined from the integrals of the ${ }^{1} \mathrm{H}-\mathrm{NMR}$ spectra versus the formaldehyde: bisphenol A ratio. The content of methylene bridges increases up to a ratio of formaldehyde to bisphenol A of 0.8. FT-IR spectra of the novolacs (Figure 5) show a band between 850 and $900 \mathrm{~cm}^{-1}$, which is not present in the spectra of bisphenol A (Figure 5 a). This band is attributed to tri- or tetrasubstituted aromatics. Further, the hydroxylic band between 3200 and $3500 \mathrm{~cm}^{-1}$ is broader in the novolac spectra than in those of bisphenol A. This means even stronger hydrogen bridges in the novolacs than in bisphenol A attributed to methylene bridges in the ortho position to the hydroxylic group in the bisphenol A structure, which is already known for other phenolic resins [23-24].

The other way of novolac preparation is the synthesis using formalin solution, bisphenol A and oxalic acid catalyst [18-19] as described above. The amounts of formaldehyde used as 37\% formalin solution and bisphenol A used in the synthesis are 3 and $1 \mathrm{~mol}$, respectively. The methylene bridge concentration of this novolac determined from the ${ }^{1} \mathrm{H}$-NMR spectrum is lower compared with the novolacs synthesized in a melting process though the formaldehyde excess is higher in the solution process. Using a formaldehyde content of 3.77 mol relative to $1 \mathrm{~mol}$ bisphenol A, the methylene bridge concentration can be increased, but high contents of hydroxymethyl groups and oxymethylene bridges were determined as 1.89 refeering to one mol of bis phenol A. Therefore synthesized, novolacs from solution process were used for the synthesis of the diglycidylether of bisphenol A [product (2)] and designated as BPFE. 


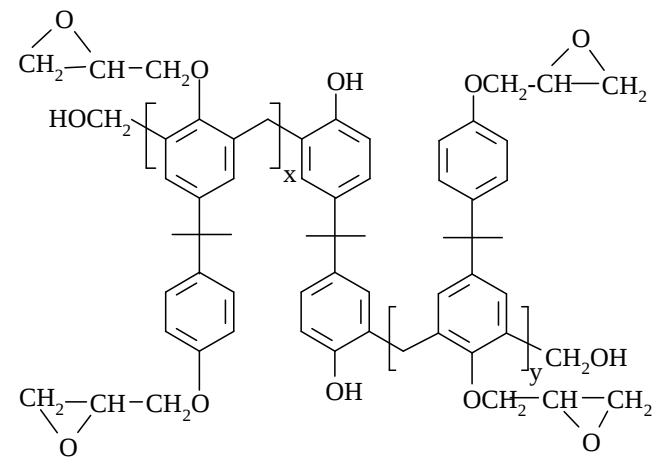

Product (2)

\section{Synthesis of Novolac BP-A epoxy resin:}

Epoxy resins are prepared by the reaction of compounds containing an active hydrogen group with epichlorohydrine (EC) followed by dehydrohalogenation in presence of $\mathrm{NaOH}$. The most commonly used epoxy resins are those derived from bisphenol-A by reaction with EC. The results of characterization of glycidyl ether derivatives of methylated bisphenol A include epoxy functionality, epoxy equivalent weight, EEW, and reaction yields are given in Table (2). It was observed that the epoxy functionality of the prepared resins was varied from 2 to 4.8. On the other hand the (Mn) determined from GPC analyses indicate that the prepared epoxy resin have low molecular weights.

These results indicate that the prepared methylated resins have polyfunctional epoxy groups.

The chemical structure of both novolacs bisphenol A epoxy resin was confirmed by ${ }^{1} \mathrm{HNMR}$ analysis. In this respect, the spectrum of BPE- 5 was represented in figure (6a). The disappearance of -OH peak at $4.7 \mathrm{ppm}$ in spectrum of $\mathrm{BP}$, figure (6b), and appearance of two peaks at $2.82 \mathrm{ppm}\left(\mathrm{CH}_{2}\right.$ epoxy), $2.94 \mathrm{ppm}\left(\mathrm{OCH}_{2}\right.$ epoxy), and $3.43 \mathrm{ppm}$ (CH epoxy) indicates the formation of glycidyl ether group [11-13].

\section{Evaluation of the prepared resins as organic coatings:}

The curing experiments, reported here, were formulated as liquid epoxy coatings with different ratios of curing agent. In all samples $1 \%$ of $(\mathrm{ET})_{3} \mathrm{~N}$ (wt\% based on weight of epoxy binder) was added as catalyst. 
The tests for measuring the mechanical properties were evaluated after $24 \mathrm{~h}$ at ambient temperature $\left(25^{\circ} \mathrm{C}\right)$. The data of mechanical properties (pull-off, impact, bending and hardens) for cured epoxy resins based on methylated bisphenol A epoxy with curing agents are listed in Table (3). The data reported on adhesions (pull-off) indicate that all cured epoxy resins based on novolacs bisphenol A epoxy resin have superior adhesion properties with steel than other cured resins. This can be attributed to the high epoxy functionality of resins and the presence of terminal glycol groups as indicated from hydroxyl numbers of the prepared epoxy binders based on novolacs bisphenol A. It has been demonstrated that the presence of small controlled amounts of terminal glycol groups can have beneficial effects on adhesion [25-26]. It was also noted that the mixing ratios between epoxy resins and AEP hardener affected the impact of coatings films. This was observed by deformation of coating films when the mol \% of AEP hardener was increased. Moreover, the films were deformed when mixing ratios for methylated epoxy resins were increased while the mixing mol ratios of epoxy: hardeners were decreased to give the best results with impact and T- bend tests. These behaviors indicate that the ratios of cross-linking agent affect the mechanical properties of coatings and the high cross-linking density networks decreases the mechanical properties of the formed network. The variation of hardness results (by pencil test) from soft (minimum cross-links) to hard coatings (maximum cross- link- density) indicate that the best results were determined at low mixing mol ratio for epoxy: hardener systems.

\section{Evaluation of chemical resistance for cured resins:}

There are two types of test methods to evaluate the durability of coatings, chemical resistance test and mechanical tests. The coated panels have subjected to chemical environments (alkali, acid, solvent and salt spray) to study the durability of coats. The data of alkali, acid, solvent- resistance and water resistance were determined for cured epoxy systems (based on methylated epoxy resins of bisphenol A) and listed in Table (4). The sign (-) indicates failure of tests, while (+) sign indicates that the coatings pass the tests. The failure of test indicates that the coating films losses their adhesion with panels and show cracking and flaking of the film.

The use of polar solvents such as ketones is often used to assess the degree of cure for a cross-linked composition for solvent resistance. In addition to immersion testing, solvent resistance may be assessed by a solvent rub test. In this respect, acetone has used to determine the degree of curing of the present coating systems by 
both immersion and rub methods. The failure of tests was determined either by disruption or dissolution of the coating films from panels. The higher the degree of cross-linking indicates the less free volume and segmental mobility remain available in the polymer. So that solvent molecules can hardly penetrate the cross-linked network at all. The crosslink density can be controlled by changing the type of curing agents and functionality of epoxy resins [27-28]. In this respect, it was found that the all prepared epoxy resins based on methylated epoxy resins of bisphenol A have good solvent resistance with all mixing ratios with AEP. It was also noted that the increasing of epoxy functionality from 2 to 4.8 for methylated epoxy resins of bisphenol A resins enhances solvent resistance for all epoxy resins / curing agents mixing ratios. This can be attributed to increasing of crosslink density by increment of epoxy functionalities, although the epoxy polarity is increased by increment of epoxy functionalities. Only specific functional groups in the polymer may cause sensitization to such reagents. The acidic hydroxyl group in phenolic resins remains sensitive to alkali even after final cure [29]. In the present systems, the structure of network based on methylated epoxy resins of bisphenol A as epoxy binders and AEP as curing agent, have aliphatic ester groups, which are sensitive to both aqueous acidic and alkaline solutions. The data of acid and alkali chemical resistance for cured methylated epoxy resins of bisphenol A indicate that these networks posses high resistance to alkaline and acidic aqueous solutions, although they have ester groups. The high alkaline and acidic resistance can be referred to high crosslink density of networks due to high epoxy functionalities. This can be attributed to high crosslink density of network decreases their exposure to environment [30]. It was also that chemical resistance of cured epoxy based on methylated epoxy resins of bisphenol A fails due to at lower mixing mol ratios the decreasing of hardener content, which decreases cross-link density of network and increase the attack of ester groups of network to acidic and alkaline solutions. On the other hand, the lower acid and base resistance of cured BPE- 5 and BPE-7.5 can be referred to the formation of dangling chains (bonded from end and free from another end) which increase the attack of ester and amide groups with both acid and alkali media [11]. The data listed in Table (5), indicate that the alkali and acid resistances were decreased when the mixing ratios between novolacs bisphenol A epoxy resin with AEP were decreased. This can be referred to the high ability to form dangling chains. 


\section{Testing Corrosion Resistance of Coating}

The continuous salt spray test was used, as described in experimental section to study the effect of salts on the properties of coating films. The duration times of tests were determined for all cured epoxy systems based methylated epoxy resins of bisphenol A and listed in Table (5). The test was stopped when the films show poor adhesion. The results of salt spray indicate the strong adhesion of coatings by the increase of epoxy functionalities. This was observed from the improvement in coating performance from 75 to $95 \%$ for BPFE after $1000 \mathrm{~h}$ of exposure to the salt spray environment. Coating performance was consistently improved for each exposure time for both coatings. This can be attributed to relationships between coating properties and performance. In this respect, the adhesion of substrate with coat is the main problem for coating failure. Strong adhesion also prevents moisture vapor from passing through the coating and condensing in a poor area of adhesion, leading to a blistering of coating. This is of particular significance when it comes to the choice of suitable coating systems. It was observed also that increasing of epoxy functionality increases the adhesion of coat with steel. This can be referred to the curing of epoxy groups with AEP hardner produce hydroxyl groups. It has been shown that the concentration of resultant hydroxyl group has a deleterious effect on the adhesion of the epoxy coating to the steel metal. The high salt spray resistance of cured epoxy resins can be attributed to the alicyclic structure of AEP that have high resistance to osmosis and electroendosmosis by comparing to aliphatic amines [31]. Essentially four types of epoxy materials are used in petroleum pipeline, tanker and marine coatings: the epoxy coal tar type coating, the amine catalyzed ambient temperature cure coating, the polyamide epoxy coating, and the epoxy ester type coating. Furthermore, an unlimited number of combinations can be formulated that are still called epoxy. In the present system of cured epoxy polyamine resins, based on both BPE-10 and BPE-15 have excellent alkali, acid and solvent resistance and provide a dense hard coating with good adhesion. So from these points epoxy resins based on novolacs bisphenol A epoxy resin can be used in linings for petroleum tanks and tankers, salt barges and ships, general chemical tankers, as well as exterior coatings for the bottoms, boot-topping, and decks. 
Table (1): Synthesis of novolac resins from bisphenol A and paraformaldehyde at varied paraformaldehyde content in a melting process.

\begin{tabular}{|l|c|c|c|c|c|}
\hline Novolac & $\begin{array}{c}\text { Paraformaldehyde } \\
\text { (mol) }\end{array}$ & $\begin{array}{c}\text { Bisphenol A } \\
\text { (mol) }\end{array}$ & $\begin{array}{c}\text { Mn } \\
(\mathbf{g} / \mathbf{m o l})\end{array}$ & $\begin{array}{c}\mathbf{T}_{\mathbf{g}} \\
\left({ }^{\circ} \mathbf{C}\right)\end{array}$ & $\begin{array}{c}\mathbf{H} \\
(\mathbf{J K} / \mathbf{g})\end{array}$ \\
\hline BP-5 & 0.167 & 0.438 & 380 & 33.0 & 0.71 \\
\hline BP-7.5 & 0.250 & 0.438 & 590 & 54.3 & 0.55 \\
\hline BP-10 & 0.330 & 0.438 & 620 & 54.4 & 0.44 \\
\hline BP-15 & 0.495 & 0.438 & 820 & 59.1 & 0.40 \\
\hline
\end{tabular}

Table (2): Physico-chemical Characterization of Glycidyl Ether of Novolacs bisphenol A.

\begin{tabular}{|l|c|c|c|c|}
\hline Oligomers & EEW & $\begin{array}{c}\text { Epoxy } \\
\text { Functionality }\end{array}$ & $\begin{array}{c}\text { Mn } \\
(\mathbf{g} / \mathbf{m o l})\end{array}$ & $\begin{array}{c}\text { Yield } \\
(\mathbf{\%})\end{array}$ \\
\hline BPE-5 & 295 & 2.0 & 590 & 73 \\
\hline BPE-7.5 & 242 & 2.8 & 680 & 62 \\
\hline BPE-10 & 243 & 3.0 & 730 & 70 \\
\hline BPE-15 & 212 & 4.8 & 1020 & 70 \\
\hline BPFE & 200 & 4.0 & 800 & 83 \\
\hline
\end{tabular}

Table (3): Coating tests of Glycidyl Ether of Novolacs bisphenol A Epoxy Resins Cured with Hardner at Different Mixing Ratios

\begin{tabular}{|l|c|c|c|c|c|}
\hline Sample & $\begin{array}{c}\text { Mol ratios } \\
\text { of BP: EAP }\end{array}$ & $\begin{array}{c}\text { Pull-off } \\
\text { MPa }\end{array}$ & $\begin{array}{c}\text { Impact } \\
(\mathbf{J} / \mathbf{m m})\end{array}$ & T-bend & Hardness \\
\hline BPE-15a & $1: 1$ & 10 & 10 & + & $\mathrm{HB}$ \\
\hline BPE-15b & $2: 1$ & 12 & 12 & + & $\mathrm{H}$ \\
\hline BPE-15c & $3: 1$ & 13 & 15 & + & $2 \mathrm{H}$ \\
\hline BPE-15d & $4: 1$ & 15 & 18 & + & $2 \mathrm{H}$ \\
\hline BPE-10a & $1: 1$ & 10 & 10 & + & $\mathrm{H}$ \\
\hline BPE-10b & $2: 1$ & 5 & 5 & + & $\mathrm{HB}$ \\
\hline BPE-10c & $3: 1$ & 3 & 1.5 & + & $\mathrm{B}$ \\
\hline BPE-10d & $4: 1$ & 3 & 1.5 & + & $\mathrm{B}$ \\
\hline BPE-7.5a & $1: 1$ & 13 & 12 & - & $\mathrm{H}$ \\
\hline BPE-7.5b & $2: 1$ & 15 & 14 & - & $\mathrm{H}$ \\
\hline BPE-7.5c & $3: 1$ & 18 & 15 & + & $2 \mathrm{H}$ \\
\hline BPE-7.5d & $4: 1$ & 20 & 20 & + & $2 \mathrm{H}$ \\
\hline BPE-5a & $1: 1$ & 15 & 12 & + & $2 \mathrm{H}$ \\
\hline BPE-5b & $2: 1$ & 8 & 8 & + & $\mathrm{H}$ \\
\hline BPE-5c & $3: 1$ & 5 & 3 & - & $\mathrm{B}$ \\
\hline BPE-5d & $4: 1$ & 5 & 3 & - & $\mathrm{B}$ \\
\hline & $1: 1$ & 7 & 10 & + & $2 \mathrm{H}$ \\
\cline { 2 - 7 } & $2: 1$ & 10 & 15 & + & $\mathrm{H}$ \\
\cline { 2 - 7 } & $3: 1$ & 12 & 20 & + & $\mathrm{H}$ \\
\cline { 2 - 7 } & $4: 1$ & 15 & 20 & + & $\mathrm{H}$ \\
\hline \multirow{2}{*}{ BPFE } & & & & \\
\hline
\end{tabular}


SYNTHESIS AND CHARACTERISATION OF BISPHENOL

215

Table (4): Chemical Resistance Tests of Glycidyl Ether of Novolacs bisphenol A

Epoxy Resins Cured with Different Mixing Rations

\begin{tabular}{|l|c|c|c|c|}
\hline Sample no. & $\begin{array}{c}\text { Acid } \\
\text { Resistance } \\
\text { (day) }\end{array}$ & $\begin{array}{c}\text { Alkaline } \\
\text { Resistance } \\
\text { (day) }\end{array}$ & $\begin{array}{c}\text { Water } \\
\text { Resistance }\end{array}$ & $\begin{array}{c}\text { Acetone } \\
\text { Rub test }\end{array}$ \\
\hline BPE-5a & 7 & 7 & - & + \\
\hline BPE-5b & 30 & 30 & + & + \\
\hline BPE-5c & 45 & 45 & + & + \\
\hline BPE-5d & 50 & 50 & + & + \\
\hline BPE-7.5a & 14 & 14 & + & + \\
\hline BPE-7.5b & 45 & 45 & + & + \\
\hline BPE-7.5c & 60 & 60 & + & + \\
\hline BPE-7.5d & 90 & 90 & + & + \\
\hline BPE-10a & 45 & 45 & + & + \\
\hline BPE-10b & 60 & 90 & + & + \\
\hline BPE-10c & 90 & 90 & + & + \\
\hline BPE-10d & 90 & 90 & + & + \\
\hline BPE-15a & 90 & 90 & + & + \\
\hline BPE-15b & 90 & 90 & + & + \\
\hline BPE-15c & 90 & 90 & + & + \\
\hline BPE-15d & 90 & 90 & + & + \\
\hline \multirow{3}{*}{ BPFE } & 90 & 90 & + & + \\
\cline { 2 - 5 } & 90 & 90 & + & + \\
\cline { 2 - 5 } & 90 & 90 & + & + \\
\hline
\end{tabular}

Table (5): Salt Spray Resistance of Cured Glycidyl Ether of Novolacs bisphenol A Epoxy Resins.

\begin{tabular}{|l|c|c|c|c|}
\hline \multirow{2}{*}{ Sample No. } & $\begin{array}{c}\text { Exposure time } \\
(\mathbf{h})\end{array}$ & \multicolumn{2}{|c|}{ Disbanded area (1) } & \multirow{2}{*}{$\begin{array}{c}\text { ASTM } \\
\text { RATING }\end{array}$} \\
\cline { 3 - 4 } BPE-5a & 300 & $\mathbf{M M}^{\mathbf{2}}$ & $\mathbf{\%}$ & 2.5 \\
\hline BPE-5b & 400 & 67.40 & 58.1 & 3.0 \\
\hline BPE-5c & 500 & 5.90 & 31.0 & 7.0 \\
\hline BPE-5d & 500 & 13.00 & 4.4 & 6.0 \\
\hline BPE-7.5a & 646 & 2.33 & 11.0 & 8.0 \\
\hline BPE-7.5b & 646 & 3.38 & 2.9 & 7.7 \\
\hline BPE-7.5c & 646 & 5.20 & 4.4 & 7.2 \\
\hline BPE-7.5d & 646 & 12.90 & 11.0 & 6.0 \\
\hline BPE-10a & 350 & 67.40 & 58.1 & 2.5 \\
\hline BPE-10b & 450 & 35.90 & 31.0 & 3.0 \\
\hline BPE-10c & 550 & 5.20 & 4.4 & 7.0 \\
\hline BPE-10d & 600 & 13.0 & 11.0 & 6.0 \\
\hline BPE-15a & 750 & 2.33 & 2.0 & 8.0 \\
\hline BPE-15b & 750 & 3.38 & 2.9 & 7.7 \\
\hline BPE-15c & 750 & 5.20 & 4.4 & 7.2 \\
\hline BPE-15d & 750 & 12.90 & 11.0 & 6.0 \\
\hline \multirow{4}{*}{ BPFE } & 1000 & 2.33 & 2.0 & 8.0 \\
\cline { 2 - 4 } & 1000 & 5.20 & 4.4 & 7.2 \\
\cline { 2 - 4 } & 1000 & 3.38 & 2.9 & 7.7 \\
\cline { 2 - 4 } & 1000 & 2.33 & 2.0 & 8.0 \\
\hline
\end{tabular}


(b)



(a)



Figure (1): GPC chromatograms of bisphenol A novolacs synthesized; a) BP-5, b) BP-10.



Figure (2): Area-\% of unreacted bisphenol $A$ in the novolacs synthesized, determined from GPC chromatograms. 


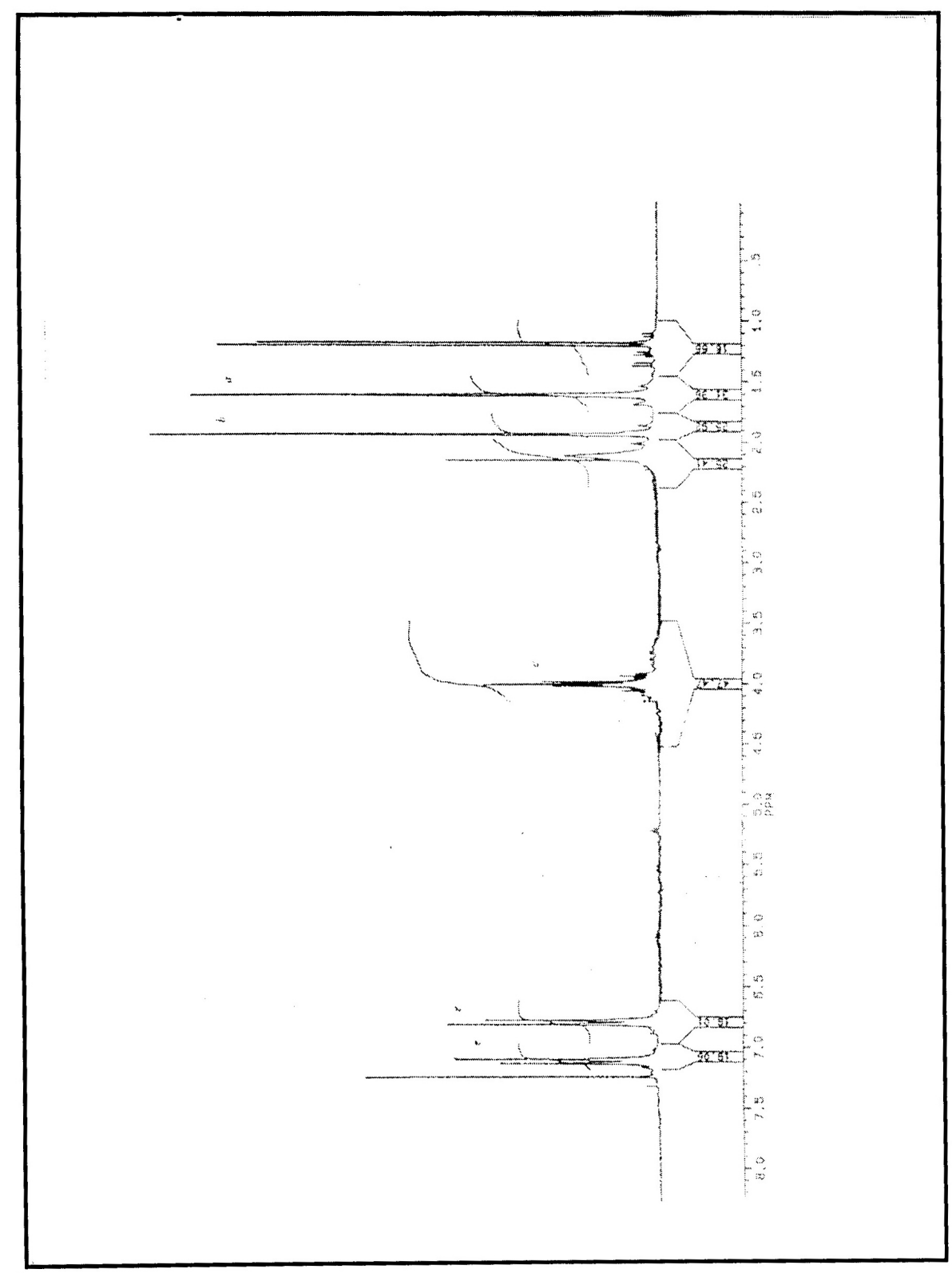

Figure (3): ${ }^{1}$ HNMR Spectrum of BP-10. 




Formaldehyde/bisphenol A ( $\mathrm{mol} / \mathrm{mol})$

Figure (4): Methylene bridge concentrations in the novolacs synthesized, calculated from ${ }^{1} \mathrm{H}$-NMR spectra.


Figure ( 5 ). FT-IR spectra; a) bisphenol A and b) BP-5. 




Figure (6 a): 'HNMR Spectrum of BPE-5.

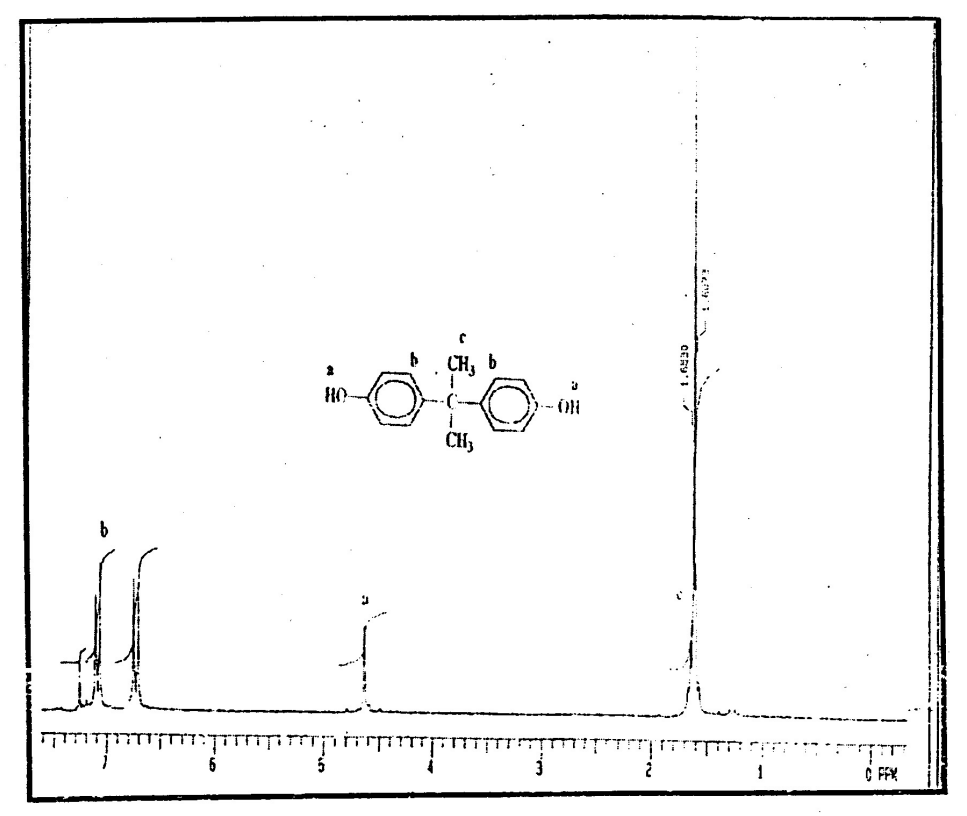

Figure (6 b): ${ }^{1} \mathrm{HNMR}$ Spectrum of BP. 
1.Greenlee. S.O. (to Devoe \& Raynolds), U.S. Pat. 2,521,912 (Sept. 12, 1950).

2.Wang. C.S. and. Liao Z.K (to the Dow Chemical Co.); U.S. Pat. 4,785,061 (Nov. 15, 1988).

3.Nelson. D. L. and Naderhoff B. A. (to the Dow Chemical Co.); U.S. Pat. 4, 394, 497 (July 19, 1983).

4.Hascgawa. K., Fukuda A., Tonogali S., Uccle K.J. Appl. Polym. Sci. 381581 (1989).

5.Hale A., Macosko C., Polym. Sci. Eng. 591196 (1988).

6.Heise. M. S., Martin G. C., Gotro J. T., J. Appl. Polym. Sci. 42, 1557 (1991).

7.Hennig. H., Dissertation, TH Merseburg (1991).

8.Laszlo-Hedvig, Zs., Molnar, I., Varadi, J., Tudos, F., Angew. Makromol. Chem. 172,37(1989).

9.Lastovica Jr., J. E., US 3142688 (1964), Dow Chemical Co., Invs.: C.A. 61 8278e. (1964).

10.Sorenson, W.R. and Campbell, TW., Preparative Method of Polymer Chemistry, Interscience, New York, 155 (1968).

11.Atta, A. M., Progress in Rubber Plastics and Recycling Technology, 19(1), 17(2003).

12.Atta, A.M., Elnagdy, S.I., Abdel-Raouf, ME., Elsaeed SM., Abdel-Azim AA, Journal of Polymer Research, Volume 12(5),373-383 (2005).

13.Atta A.M., Elnagdy SI., Abdel-Raouf ME., Elsaeed SM., Abdel-Azim AA, Progress in Organic Coatings, Volume 55, (1), Pages 50-59 (2006).

14. Knop.A., Pilato, L. A., Phenolic Resins Chemistry, Applications and Performance, Future Directions, Springer Verlag, Berlin Heidelberg, p. 31. (1985).

15.Mathes, A.O. Dissertation, Universitat Munchen (1986).

16.Nowikov, N.A., Mozolewa, A.P., Uwarov, A.B., Alekseewa, C.G., Slonim, I. Ja., Vysokomol. Soedin., Sen A 28 ,1064. (1986).

17.Mozoleva, A.P., Smirnov, W.A., Michailova, L.S., Ljapunova, N.N., Luschik, W.I.,Alexandrova, N.A., Prjachina, E.S., Lakokras. Mater. Ikh. Primen. 1989(4)13, C.A. 112,120651 r. (1990).

18.Panda, H., Rakhshinda, A.,J. Oil Colour Chem. Assoc. 65 (1982) 211, C.A. 97, 40374J (1982).

19.Ahisanuddin, S.C. Saksena, H. Panda, Rakhshinda, Paintindia 32 (1982) 3, C.A. 98,73163p (1983).

20.Braun, D., Arndt, J., Kammerer, H., Angew. Makromol. Chem. 26,181, (1972).

21.Braun, D., Arndt, J., Angew. Makromol. Chem. 73, 133(1978).

22.Braun, D., Arndt, J., Fresenius, Z., Anal. Chem. 294, 130 (1979)

23. Sprengling, GJR., J. Am. Chem. Soc. 76 ,1190 (1954) 
24. Hultzsch, M. Hesse, W., Kunststoffe 53, 166 (1963).

25. Bauer, R.S., Chemtech, 10, 692 (1980).

26. Adams, MC. and Gannon, J.A., Epoxy Resins,"In Encyclopedia of Polymer Science and Engineering, $2^{\text {nd }}$ Ed., Wiely, New York, 6, p. 322-382(1986).

27. Hare, C.V.,Protective Coatings: Fundamentals of Chemistry and Composition, Technology Publishing Co., Pittsburg, Pa., pp. 187,238. (1994).

28. Dima, IT., Miura, S., Fukuda, W. and Tomoi, M., Eur. Polym. Chem., J., 29, 1103 (1993).

29. Oldring, P.K.T., (Ed.), the Chemistry and Application of Phenolic Resins or Phenoplasts, Wiley ISITA, London (1998).

30. Masashi, K., Kazuhikon, Koichiro, O. and Takeshi, E., J. Polym. Sci., Part A: Polym. Chem., 37, 3686 (1997).

31. Meldrum, D.A. and Lin, C.T., J. Coat. Techno, 65(818), 47 (1993). 
أستخلم ايبوكسي نوفولاك البيسفينول في تطبيقات طلاء الأسطح

\title{
المعدنية
}

\author{
نيفين عمر شاكر \\ معهد بحوث البترول - قسم الاستخدامات البترولية - مدينة نصر - الثاهرة
}

المطخص:

تم تحضير نوفولاك البيسفينول بطريقة اتصهار البسفينول في وجود البارافومالدهيد وفي المحلول في وجود الفورمالين وحمض الاوكسليك كعامل حفاز. تم تعيين نسبة الميثلين بين

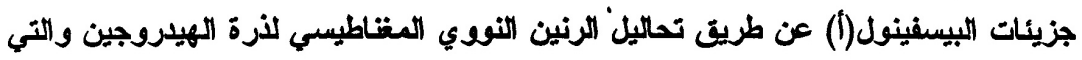



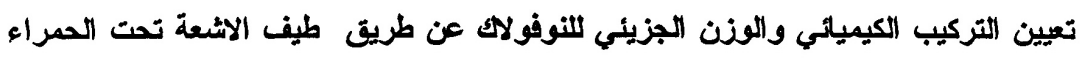
و التحليل الكروماتوجرافي. وتم بع ذلك تحضير ايبوكسيات النوفولاك عن طريف تفاعل نوفولاك بيسفينول (أ) مع هيرين ايبوكلمريد في وجود هيدروكسيد الصوديوم كعامل حفاز.

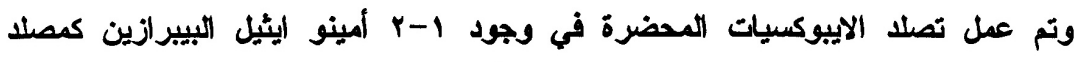
الايبوكسيات. وتم تقييم الايبوكسيات المتصلدة كأغطية خلرجية حامية للثديد من الأوساط

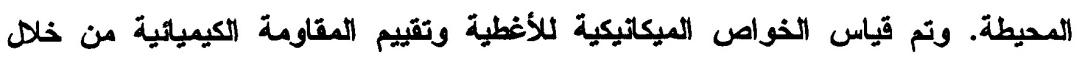
مقاومة الأغطية للأملاح والماء الساخن والمذيبت والأوساط الحمضية والقاعدية. وأئبتت المبائية

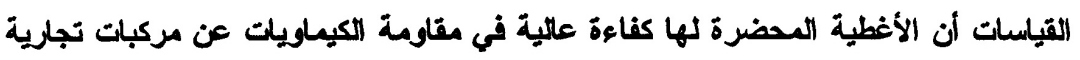
تستخدم كمواد حامية للأسطح المعدنية من الأوساط المحيطة والمسببة للتآكل 